\title{
Tecnologia assistiva para a CRIANÇA COM PARAlisia CEREbral NA ESCOLA: IDENTIFICAÇÃO DAS NECESSIDADES
}

\author{
ASSISTIVE TECHNOLOGY FOR CHILDREN WITH CEREBRAL PALSY IN SCHOOL:
} IDENTIFICATION OF NEEDS

\author{
Aila Narene Dahwache Criado ROCHA ${ }^{1}$ \\ Débora DELIBERATO²
}

\begin{abstract}
RESUMO: os estudos sobre Tecnologia Assistiva enfatizaram a necessidade de inserir recursos, serviços e estratégias na educação especial e inclusiva para colaborar com o processo de aprendizagem de alunos com deficiências. A literatura descreveu que a primeira etapa para a implementação da tecnologia assistiva na escola deve permitir entender a situação que envolve o aluno a fim de ampliar a sua participação no processo de ensino e aprendizagem. Este estudo teve como objetivo identificar as necessidades de serviços, recursos e estratégias de tecnologia assistiva para o aluno com paralisia cerebral na escola. Foram selecionadas duas crianças com paralisia cerebral e seus professores. A etapa da coleta de dados contou com três procedimentos sucessivos: entrevista com os professores, preenchimento do protocolo de identificação da rotina escolar e observação dos participantes em sala de aula realizada através de filmagens e diário de campo. A partir dos três procedimentos, foi proposta a triangulação de dados, ou seja, agrupamento das informações obtidas em um único documento para o estabelecimento das categorias de análises. Após elaboração do material, as categorias foram apreciadas por juízes da área. Os resultados demonstraram que após entender a situação do aluno com deficiência no contexto escolar foi possível estabelecer as suas habilidades e necessidades para indicar os recursos de Tecnologia Assistiva adequados ao planejamento do professor e propiciar a aprendizagem da criança com deficiência. O estudo identificou a necessidade de estabelecer procedimentos específicos, um planejamento pedagógico organizado e a participação de profissionais da saúde para o uso da tecnologia assistiva na escola.
\end{abstract}

PALAVRAS-CHAVE: Educação Especial. Paralisia Cerebral. Tecnologia Assistiva. Recursos. Educação infantil.

\begin{abstract}
Studies about Assistive Technology have emphasized the need to integrate resources, services and strategies for inclusion and special education to foster the learning process and skill development of students with disabilities. The literature describes that the first step towards implementing assistive technology in schools should enable professionals to understand the situation involving the student in order to expand his or her participation in the teaching and learning process. This study aimed to identify the need for assistive technology services, resources and strategies for students with cerebral palsy in school. Two children with cerebral palsy and their teachers were selected. The data collection phase included three successive procedures: interviews with teachers, completing the identification protocol of the school routine and participant observation conducted in the classroom using filming and field diary. Based on the material gained from these three procedures, data triangulation was proposed, i.e., grouping information in a single document in order to establish categories of analysis. After preparing the material, the categories were assessed by judges from the field of knowledge. The results showed that after understanding the situation of the disabled student within the school context, it was possible to establish his or her skills and needs to indicate the appropriate assistive technology resources for the teacher's planning and thus provide proper teaching and learning for the children with disabilities. The study identified the need to establish specific procedures, an organized pedagogical plan and participation of health professionals as consultants on using assistive technology in school.
\end{abstract}

KEYWORD: Special Education. Cerebral Palsy. Assistive Technology. Resources. Pre-school Education.

\footnotetext{
${ }_{1}^{1}$ Doutoranda do Programa de Pós-graduação em Educação, Unesp, Marilia. Terapeuta Ocupacional, Mestre em Educação. aila@marilia.unesp.br

${ }^{2}$ Docente do Departamento de Educação Especial e do Programa de Pós-graduação em Educação, Unesp, Marilia. Livre-docente em Comunicação Alternativa. delibera@marilia.unesp.br
} 


\section{INTRODUÇÃo}

Documentos internacionais e nacionais têm procurado definir a tecnologia assistiva e garantir políticas públicas que favoreçam o seu uso. Na literatura internacional as definições de tecnologia assistiva enfatizaram o uso de recursos, estratégias e serviços aplicados para atenuar os problemas funcionais encontrados pelos indivíduos com deficiências e proporcionar ou ampliar suas habilidades e, consequentemente, promover independência, qualidade de vida e inclusão (KING, 1999; LAHM; SIZEMORE, 2002; JOHNSTON; EVANS, 2005; JUDGE; FLOYD; JEFFS, 2008).

No Brasil a tecnologia assistiva é uma área de conhecimento relativamente nova e o termo ajudas técnicas aparece como sinônimo de tecnologia assistiva. $\mathrm{O}$ Comitê de Ajudas Técnicas (CAT), em ata da reunião VII DE dezembro de 2007, aprovou a adoção da seguinte conceito de Tecnologia Assistiva:

Tecnologia Assistiva é uma área do conhecimento, de característica interdisciplinar, que engloba produtos, recursos, metodologias, estratégias, práticas e serviços que objetivam promover a funcionalidade, relacionada à atividade e participação de pessoas com deficiência, incapacidades ou mobilidade reduzida, visando sua autonomia, independência, qualidade de vida e inclusão social (CAT, 2007).

As pesquisas enfatizaram a necessidade do envolvimento de profissionais especializados em diferentes áreas do conhecimento para o trabalho com pessoas com deficiência para atender as diferentes etapas dos serviços da tecnologia assistiva: avaliação e identificação das habilidades e necessidades; prescrição e confecção dos recursos; acompanhamento, bem como perceber necessidades de modificações destes recursos durante a sua utilização. Para que essas etapas de serviços se efetivem é necessário desenvolver estratégias de intervenção a fim de mediar o uso dos recursos de tecnologia assistiva nos diferentes contextos (MANZINI; SANTOS 2002; PELOSI, 2009).

A tecnologia assistiva vem conquistando um espaço importante na educação especial no Brasil e nos últimos anos pode-se observar o aumento significativo de estudos sobre esta temática. Estes estudos enfatizaram o uso de tecnologia assistiva na educação especial por meio de recursos, serviços e estratégias que colaboram com a acessibilidade, com o processo de aprendizagem e com o desenvolvimento das habilidades de alunos com deficiências (BARNES; TURNER, 2001; MANZINI; SANTOS, 2002; BERSCH, 2006; COPLEY; ZIVIANI, 2004; JUDGE, 2006; OKOLO; BOUCK, 2007; JUDGE; FLOYD; JEFFS, 2008; PELOSI 2008, 2009; GALVÃO FILHO, 2009).

Os documentos nacionais que regem a educação no Brasil, também enfatizaram que na proposta da educação especial a tecnologia assistiva tem a função de atender às especificidades dos alunos com necessidades educacionais especiais e os habilitar funcionalmente nas atividades escolares. Em relação à educação inclusiva a tecnologia assistiva está inserida com o objetivo de conduzir 
à promoção da inclusão de todos os alunos na escola. Portanto, o espaço escolar deve ser estruturado como aquele que oferece os recursos, serviços e estratégias de tecnologia assistiva (BRASIL, 2006, 2007).

Também preocupados com a sistematização do uso da tecnologia assistiva com alunos com deficiência no contexto escolar, Manzini e Santos (2002), descreveram as etapas para implementar a tecnologia assistiva na escola: entender a situação, gerar idéias, escolher alternativas, representar a idéia, construir o objeto, avaliar e posteriormente acompanhar o uso do recurso de tecnologia assistiva.

Os mesmos autores ainda alertaram que durante a implementação da tecnologia assistiva é necessário conhecer o usuário destes recursos, sua história, suas necessidades e desejos, bem como identificar quais são as necessidades reais considerando todo o seu contexto social e as possíveis barreiras que limitem a sua independência (PARETTE; BROTHERSON, 2004).

Manzini e Santos (2002) descreveram que a primeira etapa para a implementação do recurso de tecnologia assistiva na escola deve permitir ao profissional entender a situação que envolve o estudante, para isto é necessário escutar seus desejos, identificar as características físicas, psicomotoras e comunicativas, observar a dinâmica do estudante no ambiente escolar, reconhecer o contexto social e também as necessidades da professora para ampliar a participação do aluno no processo de ensino e aprendizagem.

O uso da tecnologia assistiva na escola demanda não somente o recurso, mas também um serviço que ofereça estratégias para o seu uso. As estratégias devem ter inicio anteriormente a prescrição ou construção do recurso, ou seja, é necessário observar a dinâmica do estudante no ambiente escolar e reconhecer suas necessidades. Por meio das informações do aluno, dos profissionais da escola e do ambiente é possível estabelecer critérios para elaborar recursos com perspectivas funcionais que atendam as necessidades especificas do aluno com deficiência e consequentemente diminua as taxas de abandono dos recursos de tecnologia assistiva. Neste contexto de discussão o objetivo deste estudo foi identificar as necessidades de serviços, recursos e estratégias de tecnologia assistiva para o aluno com paralisia cerebral na escola.

\section{Material e MÉtodo}

Este estudo faz parte de um projeto maior a respeito do processo de prescrição e confecção de recursos de tecnologia assistiva para crianças com paralisia cerebral no contexto da Educação Infantil aprovado pelo Comitê de Ética, sob o protocolo $n^{\circ}$. 2482/2008.

Participaram deste estudo dois alunos com paralisia cerebral e seus professores. O participante A era do gênero masculino, com três anos de idade, com diagnóstico médico de paralisia cerebral com tetraparesia espástica e atraso 
no desenvolvimento neuropsicomotor. Segundo avaliação médica apresentava baixa visão secundária à lesão no sistema nervoso central, não sendo possível avaliar precisamente a sua visão residual. Em relação à comunicação iniciou a fala após intervenção por meio de recursos da comunicação alternativa e no momento da coleta de dados embora tivesse a possibilidade de utilizar a fala, a mesma estava restrita aos contextos de suas experiências pessoais. Freqüentava classe especial para crianças com deficiência física em uma escola de educação infantil. A professora deste participante A tinha formação em pedagogia, com experiência de 23 anos, cursou habilitação em deficiência física há 17 anos e atua em classe especial para deficientes físicos há 14 anos.

$O$ participante $B$ era do gênero masculino, tinha 6 anos de idade, com diagnóstico médico de paralisia cerebral apresentando quadro discinético, com distonia generalizada e atrasono desenvolvimento motor. Em relaçãoà comunicação a criança apresentava discurso inteligível com vocalizações e emissões de algumas palavras. O aluno se comunica com o auxilio da comunicação alternativa se expressando através de pranchas de comunicação, gestos e olhar. Freqüentava sala de aula comum em uma escola de educação infantil. A professora do participante B tinha formação em pedagogia e artes, com experiência de 16 anos, não cursou nenhum curso especifico para trabalhar com crianças com necessidades especiais, embora já atuasse com crianças com deficiência há cinco anos.

As atividades vinculadas à coleta de dados foram realizadas no período de agosto de 2008 a julho de 2009, nas salas de aula da educação infantil dos participantes selecionados.

A etapa da coleta de dados contou com três procedimentos sucessivos tendo instrumentos específicos em cada uma delas. O Quadro 1 descreve os procedimentos bem como os instrumentos utilizados.

\begin{tabular}{|l|l|}
\hline Procedimentos para coleta de dados & Instrumento de coleta de dados \\
\hline Entrevistas com os professores & Roteiro de entrevista semiestruturado \\
\hline $\begin{array}{l}\text { Preenchimento pelo professor do Protocolo } \\
\text { de identificação da rotina escolar }\end{array}$ & Protocolo de Identificação da Rotina Escolar \\
\hline $\begin{array}{l}\text { Observação dos participantes em sala de } \\
\text { aula }\end{array}$ & $\begin{array}{l}\text { Filmagens } \\
\text { Registro contínuo em diário de campo }\end{array}$ \\
\hline
\end{tabular}

Quadro 1 - Procedimentos e Instrumentos para coleta de dados

O roteiro de entrevista semiestruturado foi elaborado e utilizado seguindo os cuidados estabelecidos pela literatura (MANZINI, 2004). Também foi elaborado um protocolo para registrar e identificar a rotina escolar do aluno na Educação Infantil, este instrumento teve como função registrar as diversas atividades que o 
aluno participava durante a semana na rotina escolar. $\mathrm{O}$ registro no protocolo foi feito pelo professor no decorrer da semana.

Para finalizar os procedimentos de coleta de dados foram realizados quatro encontros ao longo de um mês para observação do aluno em sala de aula, os encontros ocorreram uma vez por semana durante o período escolar para conhecer a realidade vivenciada pelo participante do estudo no contexto escolar.

Para análise das informações obtidas neste estudo foram utilizados quatro procedimentos: Transcrição dos dados da entrevista com o professor; 2. Agrupamento do conteúdo obtido através do Protocolo de Identificação de Rotina Escolar em um quadro de análise; 3. Transcrição dos dados obtidos por meio das filmagens e 4 - Organização das informações do diário de campo.

Após as informações estarem organizadas, o material foi analisado seguindo a proposta de Preto (2009). A proposta de análise estabelecida pela autora prevê a triangulação de dados segundo Triviños (1992), ou seja, agrupamento das informações obtidas em um único documento. Seguindo a proposta da análise citada, as informações obtidas na transcrição da entrevista, a organização dos dados do protocolo de rotina escolar, a transcrição dos dados da filmagem e organização das informações do diário de campo, as informações transformaramse em um texto escrito único.

Após estruturações do texto escrito foram estabelecidas categorias de análise segundo Bardin (2004), descritas no quadro 2 a seguir:

\begin{tabular}{|l|l|}
\hline \multicolumn{1}{|c|}{ Categorias } & \multicolumn{1}{c|}{ Subcategorias } \\
\hline Recursos & $\begin{array}{l}\text { 1.1. Recursos da escola } \\
\text { 1.2. Recursos adaptados da escola }\end{array}$ \\
\hline Estratégias & $\begin{array}{l}\text { 2.1. Estratégias da professora } \\
\text { 2.2. Estratégias utilizadas pelos demais membros da } \\
\text { escola }\end{array}$ \\
\hline $\begin{array}{l}\text { Participação do aluno nas } \\
\text { atividades }\end{array}$ & $\begin{array}{l}\text { 4.1. Desempenho motor } \\
\text { 4.2. Desempenho perceptivo } \\
\text { 4.3. Desempenho comunicativo }\end{array}$ \\
\hline Desempenho do aluno & \\
\hline Conduta do aluno & \\
\hline $\begin{array}{l}\text { Interlocutores mediadores do } \\
\text { aluno }\end{array}$ & \\
\hline $\begin{array}{l}\text { Ambientes das atividades realizadas } \\
\text { pelo aluno }\end{array}$ & \\
\hline
\end{tabular}

Quadro 2 - Categorias e Subcategorias de Análise 
O material foi encaminhado aos juízes com experiência na área e foram obtidos os seguintes índices de concordância segundo Carvalho (1996): pesquisador com juiz A - 86,74\%, pesquisador com juiz B - 90,47\% e juiz A com juiz B - 88,69\%.

\section{Resultados e Discussões}

Os resultados e discussões deste estudo serão apresentados seguindo as categorias identificadas durante a análise de conteúdo.

\subsection{ReCursos}

Os recursos oferecidos às crianças com paralisia cerebral podem ser fundamentais não só para as questões da aprendizagem escolar, mas também para o seu desenvolvimento global. Em função das diversas alterações que o aluno com paralisia cerebral pode apresentar, como alterações sensoriais, perceptuais, motoras, linguagem e cognitivas, os materiais devem possuir características especificas e serem atraentes para possibilita um uso funcional (BESIO, 2002; ARAUJO; MANZINI, 2001; MANZINI, 2005). O recurso adequado às especificidades dos alunos com paralisia cerebral é fundamental para sua participação efetiva na atividade proposta, sendo de responsabilidade da escola oferecer ao aluno com necessidades educacionais especiais os recursos adequados (BRASIL, 2006, 2007).

Entre os recursos mais utilizados na escola pelas professoras foram citados no Protocolo de Identificação da Rotina Escolar os seguintes objetos:

\section{Participante A}

Bolas, carrinhos e bonecas, CDs de música, baldinhos e pazinhas para areia, DVDs infantis

\section{Participante B}

Baldinhos, pazinhas, peneiras, escorregador, gira gira, ponte, balanço, gangorra, gaiola, papel bobina, caderno de linha, lápis, estojo, lousa, giz, apagador, texto digitado, tesoura, cola, bola, corda, livros, folhetos, aparelho de som, CDs, caderno de música, DVDs, fitas de vídeo, livros, fantoches, albúm seriado, carrinhos, bonecas, papeis diversos, lápis de cor, giz de cera, sucatas, bambolê e bastões.

Entre as atividades realizadas em sala de aula foi observado que embora os recursos estivessem presentes, ambos participantes não tinham como ter acesso ao seu uso e consequentemente tinham a sua participação na tarefa limitada.

Em função da falta de recursos adaptados para o participante A e os demais alunos, a professora utiliza o brincar (atividade) como recurso pedagógico. Todos os brinquedos e demais recursos citados estavam inseridos em um contexto de brincadeiras próprias da faixa etária do aluno como das demais crianças da sala. Embora a professora tenha utilizado o brinquedo e a brincadeira como 
instrumento pedagógico, o participante A necessitava de auxílio para o manuseio, ou seja, o aluno era dependente da mediação do professor par o uso do material.

Durante as observações realizadas com o participante B em sala de aula foi possível observar que em todas as tarefas nas quais o aluno necessitou destes objetos, foi necessário auxílio permanente da professora ou da estagiária. É possível identificar que o participante $\mathrm{B}$, sem a presença dos materiais escolares adaptados ou adequados a sua condição motora não tem independência para participar de uma atividade pedagógica proposta em sala de aula.

Em relação aos recursos adaptados presentes na escola foram identificados os seguintes exemplos durante as entrevistas com os professores:

\section{Participante A \\ [...] o participante A só utiliza a órtese do pé, ele traz para escola, mas em brinquedos} ou outro material escolar não [...]

[...] não tem nada especifico para ele, ai fica difícil mesmo que eu saiba qual a melhor posição fica difícil, eu sei que é preciso improvisar, mas sempre e com o material que temos é difícil, almofada, travesseiros.

\section{Participante B}

Não existe nada adaptado para ele na escola, ele realiza as atividades como as outras crianças, modifico só a maneira de fazer, ah, tem um copo que a mãe mandou.

Por meio dos exemplos citados é possível notar que o Participante A tem acesso a uso de recursos de tecnologia assistiva, como no caso da órtese. Embora a professora deste participante não tenha pontuado mobiliário adaptado para este aluno, como no caso da cadeira de roda adaptada para as medidas e características motoras especificas do aluno, ela conseguiu realizar adaptações na cadeira de rodas já existente com almofadas. O tipo de capacitação de professores para trabalhar com alunos com deficiência tem sido tema de discussão em fóruns, congressos e pesquisas (BRACCIALLI; 2008). A adaptação realizada na cadeira de rodas foi uma estratégia utilizada pela professora para ampliar as possibilidades de participação do aluno A na tarefa proposta. A estratégia utilizada pela professora foi possível em virtude não só da sua experiência com alunos com deficiência, mas pelo curso de capacitação na área da deficiência física por ela realizado - habilitação em educação especial - área da deficiência física.

A professora do participante B relatou não utilizar recursos adaptados, embora tenha indicado a necessidade de adaptar a atividade.

Nos últimos anos tem sido possível observar ênfase quanto aos aspectos ergonômicos dos mobiliários escolares, principalmente ao se deparar com alunos com deficiência física. É fundamental para criança deficiente física o posicionamento adequado através de recursos específicos que atendam as suas 
necessidades posturais, ou seja, assentos e encostos que promovam alinhamento estabilidade e conforto (BRASIL, 2007; BERSH, 2006; BEUKELMAN; MIRENDA, 2007; BRACCIALLI et al. 2008).

Durante a observação do aluno foi possível identificar que a escola do participante A oferecia possibilidades de recursos para posicionamento como: cadeiras de madeiras adaptadas, cadeiras de rodas adaptadas, cadeiras tipo cantinho, mesas com ajustes, mesas inclinadas, calça da vovó, rolos e almofadas para posicionamento.

\section{Participante A \\ [...] estava sentado em uma cadeira (tipo cantinho), com algumas almofadas apoiando}

[...] a criança foi posicionada em cadeira de madeira adaptada, com bandeja em formato de U para fazer a refeição [...]

Após a observação foi identificado um número restrito de recursos utilizado pelo participante A, e grande parte deles foram recursos utilizados para posicionamento.

Em relação ao participante $B$, a observação permitiu identificar que o recurso utilizado para o posicionamento era um andador com estrutura em aço com assento tipo fraldão e mesa de apoio para atividades. O andador era trazido de casa todos os dias. Apesar de o andador ser de uso pessoal do aluno ele não estava adequado para as suas necessidades, pois necessitava de ajustes ergonômicos, como pode ser observado pelo exemplo a seguir:

\section{Participante B}

[...] o participante B foi posicionado em seu andador em frente a uma mesa de sala de aula comum, esta com os joelhos semi fletidos e membros superiores sobre a mesa de atividades do andador, e com a cabeça baixa apoiada sobre os braços.

$\mathrm{O}$ andador utilizado pelo Participante B permitiu que ele se deslocasse pelo ambiente, porém para que isto acontecesse muitas vezes realizou movimentos inadequados, principalmente de pernas e braços, estimulados pela persistência dos reflexos primitivos. Durante as atividades também foi possível observar que o uso deste recurso não era adequado, porque estimulou os movimentos involuntários e variações na tonicidade muscular, dificultando os movimentos que a criança pretendia executar e consequentemente sua funcionalidade. Nas atividades observadas nos ambientes externos da escola, a criança se locomovia e permanecia durante todo o tempo no andador.

As referências da literatura apontaram que adequando a postura das crianças com paralisia cerebral, dando-lhes pontos de apoio e estabilidade; é possível modificar as alterações de tônus muscular e diminuir os movimentos 
involuntários e, com isto oferecer condições para que o aluno possa atuar sobre objetos e materiais escolares; consequentemente poderá permanecer com melhor contato e seguimento visual do espaço e sua atenção poderá estar direcionado para atividades mais complexas (BEUKELMAN; MIRENDA, 2007; BRASIL, 2007; BERSH, 2006).

\subsection{ESTRATÉGIAS}

Segundo políticas públicas para a educação do aluno com deficiência física na escola são necessárias recursos, estratégias que favoreçam seu processo de aprendizagem e os habilite funcionalmente na realização das tarefas escolares (BRASIL, 2006). Os pesquisadores da área da educação especial e da tecnologia assistiva também discutiram que os alunos com paralisia cerebral precisam de recursos adaptados a suas habilidades e necessidades. As pesquisas de Barnes e Turnes (2001); Pelosi (2008); Copley e Ziviani (2004); Deliberato (2005); Braccialli et al. (2008) descreveram recursos e estratégias para os alunos com paralisia cerebral e, também alertaram que embora a estrutura do programa implementado na escola possa ser o mesmo para os alunos com paralisia cerebral, os recursos e as estratégias deveriam ser adaptados para cada aluno.

A seguir é possível observar exemplos das estratégias utilizadas para envolver e facilitar a participação dos alunos.

\section{Participante A}

[...] em seguida professora movimentou sua articulação do punho e abriu a mão, neste momento colocou o carrinho na mão da criança e, junto com ela a manuseou imitando o barulho de um carro [...]

\section{Participante B}

[...] nas brincadeiras às vezes eu mudava alguma regra em função dele né, ter justamente o cuidado no correr, delimitava o espaço para não ir muito longe porque eu sabia que ele não poderia ir muito além daquilo, então de estar mudando algumas regrinhas, mas todas as coisas ali dentro do que eu sabia que ele poderia fazer $[\ldots]$

As estratégias identificadas por meio da observação do participante A e relatada pela professora do participante B durante a entrevista, permitiu verificar que as professoras realizam modificações nas regras ou formas de conduzir as brincadeiras a fim de ajustá-las as necessidades dos participantes. Essa prática é pertinente ao que existe em literatura e nas pesquisas nacionais e internacionais, alertando que a adequação das atividades as necessidades do aluno com deficiência física possibilita a autonomia, a segurança e a comunicação para que eles possam estar inseridos em turmas do ensino regular (EDYBURN, 2000; CRUZ, 2006; HUANG; SUGDEN; BEVERIDGE, 2009). 
Muitas vezes o professor tem a intenção de desenvolver estratégias adequadas, porém encontra dificuldade devido ao comprometimento da criança, ou recursos que não atendem as necessidades específicas do aluno (STEELMAN, 2002). Esta informação reforça a necessidade a importância do professor estar atento que a tecnologia assistiva deve contemplar os recursos, estratégias e serviços (BERSCH, 2006; JUDGE, 2006; OKOLO; BOUCK, 2007; JUDGE; FLOYD; JEFFS, 2008; ROCHA et al., 2008; PELOSI, 2008, 2009; GALVÃO FILHO, 2009).

A literatura nacional e internacional através de autores como Steelman (2002) e Pelosi (2009) discutiram a necessidade de programas de intervenção na escola por meio de atuações colaborativas entre os profissionais da educação e da saúde para a efetiva participação dos alunos com paralisia cerebral na escola, quer ambiente inclusivo ou no ambiente segregado. Nas pesquisas realizadas pelos autores foi possível perceber a importância do professor estar envolvido com etapas de atuação sistematizada para refletir a respeito dos recursos e estratégias necessárias.

\subsection{Participação do aluno nas atividades}

Durante a entrevista as professoras relataram que as crianças participaram das atividades, apresentaram interesse, solicitaram brinquedos e brincadeiras e foram curiosas. Os exemplos a seguir descrevem tais situações relatadas e observadas:

\section{Participante A}

Bom se ele está dentro de um contexto que ele conhece, ele lembra dos brinquedos ou brincadeiras então ele pede ou quando ele ouve uma música que fala de bola, considero essas atitudes como iniciativas. Ele pede os brinquedos quando estão com os amigos e ele quer assim como ele fez hoje com o caminhão [...]

\section{Participante B}

[...] sim ele brinca com as crianças e elas o ajudam na brincadeira o tempo todo eles não deixam ele sozinho de forma alguma mesmo quando eles estão no parque envolvidos com outras brincadeiras elas sempre dão uma passadinha ali né, tipo elas vem sentam perto para brincar com ele jamais deixam ele sozinho.

O professor deve planejar atividades onde os recursos e as estratégias utilizadas possam ampliar as possibilidades de participação do aluno, atendendo à diversidade das crianças, e assim desenvolver diferentes habilidades, interesses e maneiras de aprender no desenvolvimento de cada capacidade (BRASIL, 1998; SORO-CAMATS, 2003; PELOSI, 2009).

Durante o procedimento de observação realizado pela pesquisadora foi possível identificar que ambos os participantes demonstraram interesse pelas tarefas em todas as atividades propostas pelas professoras, mas em decorrência de suas 
características e falta de recursos, os dois participantes quase sempre se mantinham como espectadores da atividade realizada, como pode ser visualizado a seguir:

Participante A

Atividade no tanque de areia

[...] o participante A estava muito feliz e sorridente, tentava manipular a pá de areia demonstrando interesse pelo objeto, mas não conseguia desempenhar a atividade com autonomia, necessitando da ajuda da estagiaria [...]

\section{Participante B}

Atividade em sala de aula

Enquanto as demais crianças da sala abrem o seu caderno, após orientação da professora o participante B permanece esperando, sem nenhum recurso sobre a sua carteira. Em seguida o aluno estende o braço esquerdo para frente e levanta a cabeça, neste momento a professora coloca sobre a sua carteira um caderno e sai em seguida. Neste momento o Participante B direciona o olhar para as outras crianças da sala, que se encontram do seu lado esquerdo e que já estão abrindo os cadernos, realiza abdução do ombro esquerda e toca o rosto da criança que esta na carteira ao seu lado, em seguida leva a mão ate a mão da criança que esta realizando movimento para abrir seu caderno. Neste momento a criança ao lado ergue seu caderno, fazendo com que o Participante B retire sua mão.

Através destes exemplos é possível perceber que apesar das dificuldades motora, perceptivas e comunicativas os alunos apresentaram o desejo de participar da atividade, para isso criam situações lúdicas, solicitam ajuda da auxiliar e das demais crianças que estão no local naquele momento. E possível identificar que os recursos utilizados nas atividades propostas não permitiam a participação da criança com autonomia, e apesar do desejo de utilizar os recursos oferecidos necessita da ajuda constante de algum interlocutor mediador (BLANCHE, 2002; FERLAND, 2006; ROCHA et al., 2008). Neste contexto Blanche (2002) destacou a necessidade do interlocutor mediador criar estratégias a fim de viabilizar a participação da criança com paralisia cerebral durante as atividades, este procedimento permite que a criança desempenhe ações significativas e previne que o interlocutor mediador realize as tarefas de uma atividade pela criança.

\subsection{Desempenho do ALuno}

Em relação ao desempenho motor no momento da entrevista com as professoras foi possível identificar algumas situações que demonstraram a dificuldade motora da criança:

\section{Participante A}

O PA tem muita dificuldade motora ele melhorou muito, principalmente com a nova medicação que esta tomando, mas ainda tem muita dificuldade em manipular os brinquedos sempre precisa de ajuda porque os bracinhos estão sempre em flexão e mesmo quando ele consegue estender não vai muito ai precisa de alguém ajudar abrir a mãozinha dele colocar no brinquedo e ajudá-lo a sentir [...] 


\section{Participante B}

(Pesquisadora pergunta sobre como a criança explora os brinquedos) era com bastante dificuldade porque o problema justamente dele são os braços, a gente tinha que estar sempre segurando para ele colocando em algum lugar que tivesse sempre o acesso melhor para movimentação dos braços né, é a parte motora dele que é onde ele tem a maior dificuldade.

Finnie(2000) apontou as principais dificuldades dos professores de crianças com seqüelas de paralisia cerebral estão relacionadas a desenvolver atividades com tarefas que necessitam da preensão, do alcance, e da manipulação de recursos, ou seja, os professores têm dificuldades em planejar estratégias para facilitar a execução de atividades em que as crianças com paralisia cerebral necessita utilizar os membros superiores. As habilidades para executar as atividades pontuadas por Finnie (2000) têm sido instrumentos de pesquisa dos pesquisadores que buscam sistematizar padrões de motores para alunos com paralisia cerebral que facilitem a participação nas tarefas escolares e, assim facilitarem a aquisição de leitura e escrita (REGANHAN, 2006; OLIVEIRA, 2007; BRACCIALLI et al., 2008).

Durante a entrevista a professora demonstrou preferência em manter o participante B no andador durante as atividades externas. Tal preferência poderia estar associada ao fato de acreditar que ao utilizar o andador, o aluno poderia estar treinando sua marcha, como pode ser observado por meio do exemplo a seguir:

Participante B

No andador, quando é no parque que eu tiro ele do andador, ele fica na, comigo no, sem o andador, sem sapato, andando pelo parque sem sapato, para forçar ele a andar né, para esforço das perninhas, mais assim, as outras brincadeiras que eu dou tanto na quadra como no campo eu prefiro que ele fique no andador.

O exemplo demonstrou que a falta de capacitação do professor pode favorecer o uso inadequado de recursos. $\mathrm{O}$ andador do participante $\mathrm{B}$ não é um recurso adequado as suas especificidades motoras o que poderia acarretar prejuízos no processo de reabilitação do aluno do ponto de vista motor. A literatura que trata de mobiliários para alunos com paralisia cerebral enfatizou a necessidade do adequado posicionamento para diferentes atividades não só para ampliar a funcionalidade das ações dos alunos, mas também para evitar prejuízos nas aquisições motoras e prevenir deformidades (OLIVEIRA, 2007; BERSH, 2006).

As habilidades comunicativas dos alunos com paralisia cerebral no contexto escolar têm sido amplamente discutidas pela literatura nacional e internacional (VON TEZTCHNER et al, 2005; DELIBERATO, 2005). Quanto aos aspectos comunicativos as observações dos alunos permitiram identificar que os participantes A e B apresentaram diferenças significativas entre eles. A seguir serão apresentados exemplos das habilidades comunicativas: 


\title{
Participante A
}

O participante A estava brincando no tanque de areia e próximo a ele havia outras crianças, quando ele perguntou:

PB: quem ta ai? ...

[...] neste momento o aluno quis pegar a bola que estava com a professora e disse:

PB: Deixa eu pegar

\author{
Participante $B$ \\ A criança com a mão direita e corpo virado para a esquerda pega um palito e olha \\ para a estagiária. A estagiária pega o palito da mão da criança, mostra os palitos \\ que ficaram na mão dela e diz: \\ Estagiaria: Quantos ficaram aqui? \\ A criança emite som que não é possível entender, e a estagiaria diz: \\ Estagiária: AH? \\ Criança novamente emite som que não é possível entender e a estagiaria diz: \\ Estagiária: Quantos? Três (a própria estagiária responde, fazendo gesto afirmativo \\ com a cabeça). \\ Em seguida a estagiária pega o lápis e escreve o resultado no caderno da criança \\ que esta sobre a carteira, sem mostrar para aluno o que esta fazendo.
}

Por meio dos exemplos foi possível perceber que o participante A expressa intenções através da fala nas situações dialógicas, mas a estrutura dos enunciados verbais não está compatível para sua idade. Cabe ressaltar que o participante $\mathrm{A}$ apresenta além das alterações motoras dificuldades no processamento visual, ou seja, embora tenha acuidade visual nos padrões de normalidade, o aluno apresenta lesões no processamento da informação visual, acarretando prejuízo não só na realização de suas tarefas escolares, mas também no recebimento das informações ambientais necessárias para a construção do conhecimento e da linguagem (HÉCAEN, 1978).

Quanto ao desempenho comunicativo do participante B foi possível observar que aluno se expressou com maior facilidade através do olhar, em vários momentos da observação foi visto que mesmo a criança emitindo sons a professora e estagiaria apresentam dificuldade em compreender a fala do aluno. A dificuldade ficou evidente durante as duas atividades indicadas anteriormente, a primeira a professora não conseguia identificar quais as letras a criança estava indicando para formar a palavra, e na segunda atividade a estagiaria também não compreendeu o aluno quando foi necessário dizer um número.

É importante ressaltar que apesar do participante B não ter conseguido se expressar ele compreendeu as orientações que foram dadas, isto é possível ser identificado na atividade de matemática, pois apesar de sua dificuldade motora ele realizou as ações que a estagiaria indicou.

Segundo Deliberato (2005) e Von Teztchner et al (2005) a introdução de um sistema de comunicação suplementar e alternativa deve acontecer não somente 
para contemplar as questões comunicativas, mas os recursos de comunicação alternativa poderiam ser facilitadores no processo da aprendizagem significativa além de propiciar caminhos para a aquisição da leitura e escrita.

\title{
3.5 Conduta Do Aluno
}

Autores dedicados a estudar o desenvolvimento de crianças com paralisia cerebral discutiram a respeito de possibilidades de observar condutas comportamentais em função das diferentes alterações neurológicas e ambientais (MANZINI, 2005). As crianças com paralisia cerebral podem manifestar seus desejos, intenções, vontades por meio de diferentes comportamentos ou condutas. Estas condutas podem ou não ser adequadas para o ambiente de sua atividade.

Durante a entrevista as professoras relataram a sua percepção em relação à conduta das crianças no contexto escolar:

\begin{abstract}
Participante A
[...] quando a gente faz brincadeiras com as outras crianças da escola, do Infantil, do maternal ele interage sim, se comunica pede brinquedos, as crianças também conversam com ele, mas com as crianças aqui da sala é mais difícil ele é o que mais se comunica as outras crianças não se comunicam tanto, então é difícil, nós temos que trabalhar o grupo mas de forma mais individualizada, você vê né, as crianças não interagem muito entre elas, mas quando esta em atividades no parque no gramado ele interage com as crianças sim, pergunta, responde, ele fica muito feliz.
\end{abstract}

\begin{abstract}
Participante $B$
Nossa ele é, é demais, ele você vê ele buscando né, eu to explicando as atividades ele quer, ele da a opinião dele, ele quer saber, ele pergunta sim, ele é curioso demais graças a Deus ((risos da entrevistada)).

((Pesquisadora pergunta o que a criança faz quando quer alguma coisa na escola)) ele busca, ele pede o que ele quer, isso ele pede mesmo [...] ele não tem medo de nada, o bom do P2 é isso né, ele enfrenta todos os desafios.
\end{abstract}

Em relação à conduta do participante $\mathrm{A}$, a professora relatou durante a entrevista que o aluno apresentava dificuldades em interagir com as crianças de sua sala. No período de observação foi possível identificar que durante as atividades o aluno direcionava sua comunicação e expressões apenas para a professora e auxiliar. Este fato pode ter acontecido, pois as crianças que frequentavam a sala do aluno apresentavam além de deficiências motoras graves, distúrbios severos de comunicação o que dificultava a interação comunicativa entre elas.

Referente ao Participante B, no momento da entrevista a professora relatou que o aluno se envolve nas atividades sempre buscando e pedindo o que quer além de realizar perguntas quando quer saber de algum assunto. Em relação à interação do Participante B com as outras crianças a professora relatou que apesar de perceber o ciúme que as demais crianças da sala apresentam em relação 
a ela e o Participante B, acredita que a interação entre os alunos e o participante B é satisfatória. A professora também descreveu na entrevista que a criança não se sentia a vontade durante as atividades no parque, pois não conseguia realizar as tarefas motoras como as outras crianças da sala.

As escolhas das estratégias de intervenção muitas vezes estão relacionadas às habilidades da criança, sempre na tentativa de ampliar suas oportunidades em seu contexto, sua comunicação, seus parceiros, suas tarefas e sua interação. Perceber habilidades dos alunos com paralisia cerebral poderia direcionar as ações de confecção de recursos de tecnologia assistiva de forma a ampliar a participação dos alunos nas tarefas propostas e diminuir condutas inadequadas.

\subsection{AMBIENTES DAS ATIVIDADES}

Autores da educação infantil e o Referencial Curricular Nacional para a Educação Infantil também alertaram a necessidade do envolvimento das diferentes crianças nos espaços da escola que propiciem a participarem nas vivências e experiências com diferentes interlocutores e materiais disponíveis (BRASIL, 1998; MELO, 2004, 2007; LEONTIEV, 1991).

A sala de aula do participante A tinha as adequações necessárias por se tratar de uma classe especializada para alunos com deficiência neuro motora, como pode ser identificado na observação do aluno conforme o exemplo a seguir:

Participante A

A sala de aula era ampla, com boa iluminação e piso emborrachado. Em seu ambiente estavam as cadeiras adaptadas, tatame, barra paralela e acessórios como a calça da vovó, almofadas e rolos.

Por meio do exemplo acima é possível perceber que a sala de aula do aluno A contém instrumentos específicos a fim de favorecer a adequação postural não só do participante deste estudo, mas para os demais alunos com deficiência. Braccialli et al. (2008) e Oliveira (2007) discutiram em suas pesquisas há necessidade de adequações de mobiliários no contexto escolar, principalmente na sala de aula, para inserir o aluno com paralisia cerebral na rotina de atividades.

A sala de aula do participante B não dispunha de adequações físicas e de materiais para favorecer ao aluno com paralisia cerebral envolvimento nas diferentes tarefas, como pode ser visualizado por meio do exemplo a seguir:

\section{Participante $B$}

[...] as carteiras ficavam próximas uma da outra, o que dificultava a locomoção do participante B na sala de aula. O chão é de piso frio e claro, a sala é bem iluminada. Em relação a lousa, foi possível perceber que é elevada não favorecendo o campo visual do participante $B$. 
Embora os documentos oficiais designem às escolas à necessidade de adaptações e adequações para os diferentes alunos com deficiência para garantir acesso às questões pedagógicas, ainda os recursos, estratégias e serviços da área de tecnologia assistiva estão centrados nas classes especiais, salas multifuncionais, salas de recursos e, ainda nas instituições especializadas. O ambiente inclusivo é discutido pela literatura como essencial para a criança com deficiência compartilhar experiências e adquirir conhecimento, mas para que este ambiente inclusivo proporcione aprendizagem significativa, deve ser adequada à diversidade de alunos (SORO-CAMATS, 2003; PELOSI, 2009; VON TEZTCNHER et al, 2005).

\subsection{INTERLOCUTOR MEDIADOR DO ALUNO}

O professor é o responsável pela interação, contato, envolvimento e, principalmente pela mediação no processo de aprendizagem significativa do aluno na escola (LEONTIEV, 1991). A literatura também alertou que o professor deve ser o facilitador na aprendizagem do aluno, independente das suas necessidades (MANZINI, 2005; BRASIL, 2006; PELOSI, 2008, 2009). O envolvimento e capacitação do professor com a organização do planejamento e sua rotina escolar poderão garantir a adequada mediação com o aluno com paralisia cerebral.

Em relação aos participantes A e B as informações obtidas através da entrevista com a professora e do Protocolo de Identificação de Rotina Escolar foram apontados os seguintes interlocutores mediadores presentes na escola

\footnotetext{
Participante A

[...] esses dias ele perguntou algo dentro de um contexto para a M ((professora auxiliar)) ela estava falando sobre um assunto comigo.
}

Professora, duas professoras auxiliares, o motorista da perua durante o transporte e uma ajudante para o transporte.

Participante B

Professor. Quando disponível estagiária que atende a escola.

As professoras dos dois participantes não indicaram durante os exemplos acima as demais crianças da escola como interlocutores mediadores das atividades desenvolvidas. É necessário que o professor ofereça oportunidades para que a criança com paralisia cerebral amplie a sua relação com diferentes interlocutores, entre eles as os alunos da escola. A mediação necessária para os alunos com paralisia cerebral nas atividades poderiam ser feitas por professores, profissionais da escola e alunos competentes em habilidades específicas, como por exemplo, em habilidades motoras para auxiliar o aluno com alteração neuro motoras na realização de uma tarefa que depende de atos motores. 
Teixeira; Ariga; Yassuko (2003) e Ferland (2006) discutiram que as crianças constroem o conhecimento a partir da relação com as diferentes pessoas, no caso as atividades e as brincadeiras com outras crianças podem favorecer o desenvolvimento da linguagem, a curiosidade, o prazer e a imaginação, compondo a sua inteligência e adquirindo conceitos pré requisitos para a leitura e escrita.

A literatura da área advertiu a necessidade de capacitar os diferentes interlocutores e mediadores para favorecer o uso adequado dos recursos e estratégias da tecnologia assistiva (MANZINI, 2005; PELOSI, 2008, 2009). Neste contexto de discussão, a estagiária, motorista e auxiliar de sala poderiam ser mediadores no processo de ensino dos diferentes alunos em função das tarefas estabelecidas na rotina.

\section{Conclusões}

O estudo permitiu indicar que: 1 . as informações obtidas por meio do relato dos professores favoreceram a descrição das especificidades do aluno e do ambiente; 2. A caracterização dos alunos e do ambiente é fundamental para a confecção dos recursos; 3. A importância da capacitação do professor não só para o uso dos recursos, mas para estabelecer as estratégias de uso dos materiais; 4. $\mathrm{O}$ ambiente da classe especial favoreceu a disponibilidade de recursos, mas não garantiu a generalização do uso dos instrumentos frente à rotina do professor; 5. O ambiente inclusivo favoreceu a interação do aluno com paralisia cerebral com outros interlocutores competentes em diversas habilidades; 6 . $\mathrm{O}$ ambiente inclusivo não favoreceu a disponibilidade de recursos.

\section{CONSIDERAÇÕES FINAIS}

O entendimento do contexto e situação do aluno com deficiência na escola é fundamental para a prescrição, construção, adaptação e implementação dos recursos de tecnologia assistiva. Neste estudo os alunos foram os protagonistas deste processo, porém foi necessário perceber as demandas do ambiente e as necessidades do professor. A partir destes fatores foi possível pensar em recursos com potencial pedagógico que viabilizassem experiências significativas para o processo de aprendizagem do aluno.

É fundamental destacar a importância dos três procedimentos de coleta de dados projetados para este estudo, pois essa abordagem permitiu que a situação fosse examinada através de métodos diferentes, o que foi essencial para contemplar o objetivo proposto nesta pesquisa. A triangulação dos dados favoreceu a validade e a fidedignidade das informações agrupando fontes múltiplas de dados, o que permitiu abranger maior amplitude do tema em estudo.

As categorias identificadas durante o processo de entendimento da situação possibilitam aos profissionais o direcionamento para a indicação e uso 
de recursos e estratégias de tecnologia assistiva junto à criança com paralisia cerebral no ambiente escolar. $O$ estudo reforçou a necessidade da escola e do professor perceberem que o uso de recursos de tecnologia assistiva envolve serviços diferenciados, principalmente recursos humanos da área da saúde e um planejamento organizado vinculado à rotina escolar a fim de favorecer o uso funcional da tecnologia assistiva.

\section{REFERÊNCIAS}

ANDRÉ, M. E. D. A. Texto, contexto e significados: algumas questões na análise de dados qualitativos. Caderno de Pesquisa., São Paulo, v.45, p.66-71, 1983.

ARAÚJO, R.C.T.; MANZINI, E.J. Recursos de ensino na escolarização do aluno deficiente físico. In: MANZINI E.J. (Org.). Linguagem, cognição e Ensino do Aluno com Deficiência. Unesp, 2001, p.1-11.

BARDIN, L. Análise de conteúdo. Tradução de Luís Reto e Augusto Pinheiro. Lisboa: Edições 70, 2004.

BARNES, K. J.; TURNER, K. D. Team collaborative practices between teachers and occupational therapist. The American Journal of Occupational Therapy., United States, v.55, n.1, p.83-89, 2001.

BEUKELMAN, D. R.; MIRENDA, P. Augmentative $\mathcal{E}$ alternative communication: supporting children \& adults with complex communication needs. Baltimore: Paul H. Brookes Publishing, 2007.

BERSCH, R. Tecnologia assistiva e educação inclusiva. In: Ensaios Pedagógicos. Brasília: SEESP/MEC, 2006, p. 89-94.

$\mathrm{BESIO}, \mathrm{S}$. An Italian research project to study the play of children with motor disabilities: the first year of activity. Disability and Rehabilitation, v.24, n.1, 2002, p.72-79.

BLANCHE, E. I. Play and process: Adult play embedded in the daily routine. In J. Roopnarire (Ed.). Conceptual, social-cognitive, and contextual issues in the field of play. Conn: Ablex Publishing, 2002.

BRACCIALLI, L. M. P. Tecnologia assistiva: perspectiva de qualidade de vida para pessoas com deficiência. In: Vilarta, R.; Guierrez, G.L.; Carvalho, T.H.P.F.; Gonçalves, A. (Org.). Qualidade de vida e novas tecnologias. Campinas: IPES, 2007. p.105-114.

BRACIALLI et al. Influencia do assento da cadeira adaptada na execução de uma tarefa de manuseio. Revista Brasileira de Educação Especial. Marília: ABPEE, v.1, n.14, p.141154, 2008.

BRASIL. Referencial curricular nacional para a educação infantil. Brasília: Ministério da Educação MEC/SEF, 1998.

Sala de Recursos Multifuncionais: espaços para o Atendimento Educacional Especializado. Brasília: MEC/SEESP, 2006.

. Atendimento Educacional Especializado - Deficiência Física. Brasília: MEC/SEESP/ SEED, 2007. 
CARVALHO, A. M. P. O uso do vídeo na tomada de dados: pesquisando o desenvolvimento do ensino em sala de aula. Pro-posições, v.7, n.1, p.5-13, 1996.

CAT - Comitê de Ajudas Técnicas. Ata da Reunião VII, de dezembro de 2007 do Comitê de Ajudas Técnicas. Secretaria Especial dos Direitos Humanos da Presidência da República (CORDE/SEDH/PR), 2007. Disponível em: <http:/ / http:/ / www.mj.gov.br/ corde/comite.aspAcesso em: 16 set. 2009.

COPLEY, J.; ZIVIANI, J. Barriers to the use of assistive technology for children with multiple disabilities. Occupational Therapy International. United States, v.11, n.4, p.229-243, 2004.

CRUZ, D. M. C. Brincar é estimular? Preensão, função manual e sua estimulação em pré escolares com paralisia cerebral do tipo hemiparesia espástica. 2006. 152f. Dissertação (Mestrado em Educação Especial) - Universidade Federal de São Carlos, São Carlos, 2006.

DELIBERATO, D. Speech and language therapy in the school: resources and procedures for augmentative and alternative communication. In: VON TETZCHNER, S.; GONÇALVES, M. J. (ed.). Theoretical and methodological issues in research on augmentative and alternative communication. Canada: ISAAC, 2005. p.116-125.

EDYBURN, D. L. Assistive technology and students with mild disabilities. Focus on Exceptional Children, v. 32, n.9, p. 1-23, 2000.

ELIASSON, A. C.; KRUMLINDE-SUNDHOLM, L., ROSBLAD, B., BECKUNG, E., ARNER, M., OHRVALL, A. M. The Manual Ability Classification System (MACS) for children with cerebral palsy: scale development and evidence of validity and reliability. Dev Med Child Neurol. v.48, n.7, p.549-554, 2006.

FERLAND, F. O Modelo lúdico: o brincar, a criança com deficiência física e a terapia ocupacional. São Paulo: Editora Roca, 2006.

FINNIE, N. R. O manuseio em casa da criança com paralisia cerebral. 3. ed. São Paulo: Manole, 2000.

GALVÃO FILHO, T. A.Tecnologia Assistiva para uma escola inclusiva: apropriação, demandas e perspectivas. 2009. 346f. Tese (Doutorado em educação) - Faculdade de Educação, Universidade Federal da Bahia, 2009.

GITLIN, L. N. Why older people accept or reject assistive technology. Generationsv. v.19, p.4147, 1995.

HUANG, I.C.; SUGDEN, D.; BEVERIDGE, S. Assistive devices and cerebral palsy: factors influencing the use of assistive devices at home by children with cerebral palsy. Child: Care, Health \& Development. v.35, n. 1, p.130-139, 2009.

JOHNSTON, S.S.; EVANS, J. Considering response efficiency as a strategy to prevent assistive technology abandonment. Journal of Special Education Technology, v.20, n.3, p.4550, 2005.

JUDGE, S. Constructing an assistive technology toolkit for young children: Views from the field. Journal of Special Education Technology. United States v.21, n.4, p.17-21, 2006.

JUDGE S.; FLOYD, K.; JEFFS T. Using an Assistive Technology Toolkit to Promote Inclusion. Early Childhood Educ J., United States, v.36, p.121-126, 2008. 
KING, T.W. Assistive Technology: essential human factors. Boston: Allyn and Bacon, 1999. LAHM, E. A.; SIZEMORE, L. Factors that influence assistive technology decision-making. Journal of Special Education Technology, United States, v.17, n.1, p.15-26, 2002.

LEONTIEV, A. N. Uma contribuição à teoria do desenvolvimento da psique infantil. In: LURIA, A. R., LEONTIEV, A. N, VYGOTSKY, L. S. In: Psicologia e Pedagogia: bases psicológicas da aprendizagem e do desenvolvimento. São Paulo: Moraes, 1991. p.59-83.

MANZINI, E. J. Tecnologia assistiva para educação: recursos pedagógicos adaptados. In: Ensaios pedagógicos: construindo escolas inclusivas. Brasília: SEESP/MEC, 2005. p. 82-86.

. Entrevista semi-estruturada: análise de objetivos e de roteiros. In: SEMINÁRIO INTERNACIONAL DE PESQUISA E ESTUDOS, 2., A pesquisa qualitativa em debate. Anais... Bauru: SIPEQ, 2004. 1CD.

MANZINI, E. J. ; SANTOS, M. C. F. Portal de ajudas técnicas para a educação: equipamento e material pedagógico para educação, capacitação e recreação da pessoa com deficiência recursos pedagógicos adaptados. 1. ed. Brasília: MEC, 2002. v.1.

MANZINI, E. J.; DELIBERATO, D. Portal de ajudas técnicas para a educação: equipamento e material pedagógico para educação, capacitação e recreação da pessoa com deficiência física - recursos para a comunicação alternativa. Brasília: MEC, Secretaria de Educação Especial, 2004. Fasc. 2.

Portal de ajudas técnicas para a educação: equipamento e material pedagógico para educação, capacitação e recreação da pessoa com deficiência física - recursos pedagógicos II. Brasília: MEC, Secretaria de Educação Especial, 2007. Fasc. 4.

OKOLO, C. M.; BOUCK, E. C. Research about assistive technology: 2000-2006. What have we learned? Journal of Special Education Technology. v.22, n.3, p.19-34, 2007.

OLIVEIRA, F. T. Estudo do mobiliário escolar durante o desempenho de atividades lúdicas por alunos com paralisia cerebral espástica. 2007. 100f. Dissertação (Mestrado) - Faculdade de Filosofia e Ciências, Universidade Estadual Paulista, Marília, 2007.

PARETTE, H. P.; BROTHERSON, M. J. Family-centered and Culturally Responsive Assistive Technology Decision Making. Infants \& Young Children, v. 17, n.4, p.355-367, 2004.

PELOSI, M. B. A. Inclusão e Tecnologia Assistiva. 2008. Volumes I e II, 303f. Tese (Doutorado em Educação) - Programa de Pós-graduação em Educação da Faculdade de Educação, Universidade do Estado do Rio de Janeiro, Rio de Janeiro, 2008.

. Tecnologias em comunicação alternativa sob o enfoque da terapia ocupacional.

In: DELIBERATO, D.; GONÇALVES, M. J.; MACEDO; E. C. (Org.). Comunicação alternativa: teoria, prática, tecnologias e pesquisa. São Paulo: Memnon Edições Científicas, 2009. p. 163-173.

PRETO, V. O. Adaptação de livros de literatura infantil para alunos com deficiência visual. 2009. 237f. Dissertação (Mestrado) - Faculdade de Filosofia e Ciências, Universidade Estadual Paulista, Marília, 2009.

REGANHAM, W. G. Recurso e estratégia para o ensino de alunos com deficiências: percepção de professores. Dissertação (Mestrado em Educação) - Faculdade de Filosofia e Ciência, Universidade Estadual Paulista, Marília, 2006. 
ROCHA, A. N. D. C., et al. D. Tecnologia assistiva e a experiência lúdica: o uso do brinquedo adaptado como possibilidade terapêutica para o desenvolvimento da criança In: CONGRESSO BRASILEIRO DE EDUCAÇÃO ESPECIAL, 3., E ENCONTRO DE PESQUISADORES EM EDUCAÇÃO ESPECIAL, 4., 2008, São Carlos. Anais. São Carlos, 2008. v.1. p.1 - 10.

SCHWARTZWAN, J. S. Paralisia Cerebral. Arquivos Brasileiros de Paralisia Cerebral, São Paulo, v.1, n.1, p.5-17, 2004.

SILVA, M. O. Protocolo para prescrição ou adaptação de recursos pedagógicos para alunos com paralisia cerebral. 2010. 195f. Dissertação (Mestrado em Educação) - Faculdade de Filosofia e Ciências, Universidade Estadual Paulista, Marília, 2010.

SORO-CAMATS, E. Uso de ajudas técnicas para a comunicação, o jogo, a mobilidade e o controle do meio: uma abordagem habilitadora. In: ALMIRALL, C. B.; SORO-CAMATS, E.; BULTÓ, C. R. (Org.). Sistemas de sinais e ajudas técnicas para a comunicação alternativa e a escrita: princípios teóricos e aplicações. São Paulo: Livraria Santos Editora, 2003. p. 23-41.

STEELMAN, J. D. Assistive Technology: Good for all students. Principal Leader Ship (Midlle Level ed.) Reston, v.3, p.62-66, 2002.

TEIXEIRA, E.; ARIGA, M.; YASSUKO, R. Adaptações. In: TEIXEIRA, E. et al. Terapia ocupacional na reabilitação física. São Paulo: Roca, 2003. p. 129-173.

TRIVIÑOS, A. N. S. Introdução à pesquisa em ciências sociais: a pesquisa qualitativa em educação. 3 ed. São Paulo: Atlas, 1992.

VON TETZCHNER, S et al. Inclusão de crianças em educação pré-escolar regular utilizando comunicação suplementar e alternativa. Revista Brasileira de Educação Especial, Marilia, v.11, n.2, p.151-184, 2005.

Recebido em: 22/03/2011

Reformulado em: 27/08/2011

Aprovado em: 14/10/2011 
ROCHA, A. N. D. C.; DELIBETATO, D. 